\title{
Solubility Enhancement of Gluten by Arginine: Thermodynamics and Solute Solvent-Interactions
}

\author{
SUSHREE TRIPATHY ${ }^{\mathrm{a}}$, MINAKETAN TRIPATHY ${ }^{\mathrm{b}}$, \\ PRAVIN KUMAR KAR ${ }^{* a}$ and ABU BAKAR ABDUL MAJEED ${ }^{b}$
}

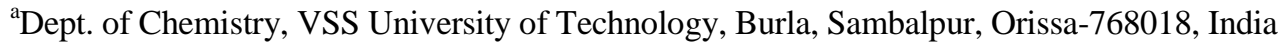

${ }^{\mathrm{b}}$ Faculty of Pharmacy, Puncak Alam Campus, Universiti Teknologi MARA-42300, Malaysia drpravinkumarkar@hotmail.com

Received 9 July 2012 / Accepted 29 July 2012

\begin{abstract}
Arginine has been shown to suppress the aggregation of proteins. Here the aquous solubility enhancement of highly insoluble protein "gluten" in presence of arginine was re-examined. Further in order to understand the thermodynamics and solute solvent interactions during the solubility enhancement of gluten in presence of arginine, the ternary system has been subjected to conductometric measurements. The conductance values have been used to evaluate the limiting molar conductance and association constants by means of Shedlovsky extrapolation technique. The thermodynamic parameters for the association process of arginine in presence of gluten in water have also been calculated. A concentration dependence solubility enhancement of gluten was observed. It was observed that, arginine enhances the solubility of gluten by 15.71 folds as compared to that in water.
\end{abstract}

Keywords: Gluten, Arginine, Limiting molar conductance, Association constant

\section{Introduction}

Arginine has been examined for its ability to suppress the aggregation of proteins and adsorption of proteins to the solid surface ${ }^{1,2}$. The elution of bound proteins has been facilitated from various chromatographic columns ${ }^{3,4}$. Arginine disrupts protein- protein and protein surface interactions. Gluten is a highly insoluble protein derived from the cereal wheat. This protein is typical of wheat varieties with good baking properties. The solubility enhancement of gluten in presence of arginine in phosphate buffer $\mathrm{pH} 7$ has been reported ${ }^{5}$. It has been indicated that arginine undergoes weak binding to the protein surface ${ }^{6-8}$. Although there is no clear mechanism for such an affinity of arginine to protein surface, previous research have indicated the binding of arginine to aromatic groups involving $\pi$ electroncation interaction $^{9,10}$. A thorough literature study reveals that no detailed explanations in terms of solute solvent interaction have been made and the related thermodynamic parameters have not been reported. Hence the present work intends to re-examine the solubility enhancement of gluten in water and also to perform the conductometric measurements of the sample, as the conductance measurements of solutes at definite and infinite dilutions in a solvent system provide valuable information about the ion-ion and ion-solvent interactions. 
By examining the limiting molar conductivity $\left(\wedge_{0}\right)$, association constant $\left(\mathrm{K}_{\mathrm{A}}\right)$ and the related thermodynamic parameters $\left(\Delta \mathrm{G}^{0}, \Delta \mathrm{H}^{0}, \Delta \mathrm{S}^{0}\right.$ and $\left.\mathrm{Ea}\right)$ of ionic solutions as function of size, nature, temperature and composition of the solvent, it is possible to examine the parameters on solute-solvent interaction for better understanding of the interactions in solutions ${ }^{11,12}$.

\section{Experimental}

Gluten, guanidine hydrochloride $(\mathrm{Gdn} \mathrm{HCl})$ and arginine were obtained from Sigma. The solutions were prepared freshly by mass using a Metler balance with a precision of $0.01 \mathrm{mg}$ in doubly distilled deionized and degassed water. The conversion of molality to molarity was done by standard expression ${ }^{13}$.

\section{Solubility study}

Test solvents were prepared separately taking different concentrations $(0.1$ to $0.5 \mathrm{M})$ of arginine in DDW and were denoted as S1 to S5. For the solubility study of gluten in arginine a previously reported method $^{6}$ was followed with modification. Gluten powder was homogenised at $20 \mathrm{mg} / \mathrm{mL}$ in $1 \mathrm{mM} \mathrm{HCl}$. An $1 \mathrm{~mL}$ aliquot (20 mg of gluten) was suspended in to $100 \mathrm{~mL}$ of test solvents, using a $100 \mathrm{~mL}$ conical flask. All the conical flasks were put in a mechanical shaker maintained at the temperature of $308.15 \mathrm{~K}$, within an accuracy of $\pm 0.02 \mathrm{~K}$ and shaken for a maximum period of 72 hours and then centrifuged followed by filtration. The suitable amount of the filtrate was mixed with one volume of $6 \mathrm{M} \mathrm{Gdn} \mathrm{HCl}$ to minimize light scattering. The gluten concentration from the mixture was obtained by measuring the absorbance at $280 \mathrm{~nm}$ and relative solubility measurement was done considering the amount of gluten solubilised by $6 \mathrm{M} \mathrm{Gdn} \mathrm{HCl}$ as $100 \%$. All the experiments were carried out in triplicate.

Further the respective filtrates were subjected to conductometric analysis, using a conductivity meter with accuracy of $\pm 0.5 \%$ and a conductivity cell (Model-Eutech instruments, pc-510). The conductance cell was equipped with a water circulating jacket, and the temperature was controlled within $\pm 0.02 \mathrm{~K}$ in a water thermostat. The cell constant is $1.01 \mathrm{~cm}^{-1}$ which was calculated by repeated measurements of $\mathrm{KCl}$ solutions. All data were corrected with specific conductivity of pure water at the experimental temperatures. The different molar solutions of arginine without gluten were also measured for the specific conductivities. For each sample six data points were considered to calculate the average, which was further used to calculate the equivalent conductance for the samples.

\section{Results and Discussion}

The results of the solubility measurements of gluten in different test solutions are shown in Table 1. A $0.2 \mathrm{mg} / \mathrm{mL}$ gluten in $6 \mathrm{M} \mathrm{Gdn} \mathrm{HCl}$ showed a clear solution and the corresponding absorbance was considered as $100 \%$. It is seen that the solubility of gluten is significantly higher in presence of arginine than that in pure water. The solubility enhancement was observed to be concentration dependent. The above trend is in agreement with the findings of the previous literature. The dissolution of a solute (gluten) in presence of a co-solute (arginine) in ternary solutions may be explained in the light of (i) hydrophilic -ionic interactions between the hydrophilic sites (amide, carboxylic, hydroxyl and carbonyl) of gluten and the ions of the co-solute, and (ii) hydrophobic -ionic interactions between the hydrophobic parts of the gluten molecules and the ions of the co-solute. According to the cosphere overlap model ${ }^{13,14}$, type (i) interactions favour the dissolution of gluten in presence of arginine. 
Table 1. Solubility data of gluten in water and different molar concentrations of arginine

\begin{tabular}{cc}
\hline Solvent system & Solubilization, \% \\
\hline water & 4.2 \\
(S1) 0.1 M Arginine & 36 \\
(S2) 0.2 M Arginine & 42 \\
(S3) 0.3 M Arginine & 48 \\
(S4) 0.4 M Arginine & 54 \\
(S5) 0.5 M Arginine & 66 \\
\hline
\end{tabular}

The solubility data is relative to the solubilization of gluten in $6 \mathrm{M} \mathrm{Gdn} \mathrm{HCl}$ as considered $100 \%$

The molar conductance $(\Lambda)$ data of different molar solutions (0.1-0.5 M) of arginine in presence and absence of gluten are listed in Table 2. The experimental data of the conductance measurements for the aqueous solutions of arginine without and with gluten after solvent correction were analyzed using Shedlovsky ${ }^{15}$ and Fuoss-Kraus ${ }^{16,17}$ extrapolation techniques. As the limiting molar conductivity values, $\wedge_{0}$ obtained by two methods using the values of ion-size parameter, $\mathrm{a}_{0}=0, \mathrm{q}$ and $2 \mathrm{q}$ are very close to each other, as presented by Das et.al. ${ }^{11}$, the values of the $\left(\Lambda_{0}\right)$ for $\mathrm{a}_{0}=\mathrm{q}$ are given in Table 2 for the Shedlovsky method only and so also the values of $\mathrm{K}_{\mathrm{A}}$, the association constants (Table 3 ) of arginine and also of gluten in aqueous solutions of arginine at experimental temperatures.

Table 2. The values of molar conductance $\Lambda\left(\mathrm{s} \mathrm{cm}^{2}\right)$, limiting molar conductance $\Lambda_{0}$ $\left(\mathrm{s} \mathrm{cm}^{2} \mathrm{~mol}^{-1}\right)$ and activation energy Ea $\left(\mathrm{k} \mathrm{J} \mathrm{mol}^{-1}\right)$

\begin{tabular}{|c|c|c|c|c|c|}
\hline \multirow{2}{*}{$\begin{array}{l}\text { Solvent } \\
\text { system }\end{array}$} & \multicolumn{4}{|c|}{$\Lambda, \mathrm{s} \mathrm{cm}^{2}$} & \multirow{2}{*}{$\begin{array}{c}\mathrm{Ea} \\
\mathrm{k} \mathrm{J} \mathrm{mol}^{-1} \\
\end{array}$} \\
\hline & T/K 298.15 & 303.15 & 308.15 & 313.15 & \\
\hline \multicolumn{6}{|c|}{ (A) } \\
\hline S1 & 0.166 & 0.191 & 0.221 & 0.249 & 21.18 \\
\hline S2 & 0.108 & 0.113 & 0.124 & 0.136 & 12.18 \\
\hline S3 & 0.082 & 0.085 & 0.088 & 0.097 & 8.32 \\
\hline S4 & 0.066 & 0.068 & 0.072 & 0.076 & 7.31 \\
\hline S5 & 0.126 & 0.131 & 0.138 & 0.141 & 5.92 \\
\hline$\Lambda_{0,} \mathrm{~s} \mathrm{~cm}^{2} \mathrm{~mol}^{-1}$ & 0.188 & $\begin{array}{l}0.221 \\
\text { (B) }\end{array}$ & 0.265 & 0.309 & -2.53 \\
\hline S1 & 0.536 & 0.552 & 0.565 & 0.576 & 3.74 \\
\hline S2 & 0.275 & 0.287 & 0.294 & 0.295 & 3.57 \\
\hline S3 & 0.153 & 0.157 & 0.158 & 0.159 & 1.70 \\
\hline S4 & 0.112 & 0.117 & 0.121 & 0.123 & 5.08 \\
\hline S5 & 0.125 & 0.127 & 0.129 & 0.132 & 3.06 \\
\hline 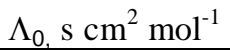 & 0.806 & 0.833 & 0.853 & 0.866 & 3.66 \\
\hline
\end{tabular}

(A) Arginine only (B) Arginine + Gluten

The obtained limiting molar conductivities of the solutions containing arginine, in absence and presence of gluten are summarized in Table 2. It can be seen from Table 2 that the limiting molar conductance $\left(\Lambda_{0}\right)$ values in case of different arginine solutions are comparatively lower than that of the systems in presence of gluten. However with increase in temperature, both in absence and in presence of gluten the $\Lambda_{0}$ values were observed to increase. This observation can be ascribed to the fact that, an increase in microscopic viscosity 
of the medium, with an increase in arginine concentration increases the frictional coefficient of the medium thereby retarding the mobility of the ions in solutions ${ }^{18,19}$ whereas in presence of gluten, a preferential molecular aggregation takes place involving both arginine and gluten, as a result of which, the hydrodynamic radii of the ions (generated from arginine) decrease, resulting a decrease in microscopic viscosity of the medium and enhancing the mobility of the ions ${ }^{19}$.

A perusal of Table 3 shows that association constants are positive in the arginine solutions at all experimental temperatures and also in presence of gluten except that of the lower concentrations at temperatures of $298.15 \mathrm{~K}, 303.15 \mathrm{~K}$ and $313.15 \mathrm{~K}$.

Since the conductance measurements of an ion depend upon mobility, it is quite reasonable $e^{20}$ to treat the conductance data similar to the one employed for the rate process taking place with the change of temperature, i.e.,

$$
\Lambda_{0}=\mathrm{A} \mathrm{e} \mathrm{e}^{-\mathrm{Ea} / \mathrm{RT}} \text { or } \log \Lambda_{0}=\log \mathrm{A}-\mathrm{Ea} / 2.303 \mathrm{RT}
$$

Table 3. The values of association constants $\mathrm{K}_{\mathrm{A}}\left(\mathrm{dm}^{3} \mathrm{~mol}^{-1}\right)$ at 4 different temperature and thermodynamic parameters, $\Delta \mathrm{G}^{0}\left(\mathrm{~kJ} \mathrm{~mol}^{-1}\right), \Delta \mathrm{H}^{0}\left(\mathrm{~kJ} \mathrm{~mol}^{-1}\right)$ and $\Delta \mathrm{S}^{0}\left(\mathrm{~kJ} \mathrm{~mol}^{-1} \mathrm{~K}^{-1}\right)$ at $298.15 \mathrm{~K}$

\begin{tabular}{|c|c|c|c|c|c|c|c|}
\hline $\begin{array}{l}\text { Solvent } \\
\text { system }\end{array}$ & \multicolumn{3}{|c|}{$\mathrm{K}_{\mathrm{A}}, \mathrm{dm}^{3} \mathrm{~mol}^{-1}$} & & $\begin{array}{c}\Delta \mathrm{G}^{0} \\
\mathrm{~kJ} \mathrm{~mol}^{-1}\end{array}$ & $\begin{array}{c}\Delta \mathrm{H}^{0} \\
\mathrm{~kJ} \mathrm{~mol}^{-1}\end{array}$ & $\begin{array}{c}\Delta \mathrm{S}^{0} \\
\mathrm{~kJ} \mathrm{~mol}^{-1} \mathrm{~K}^{-1}\end{array}$ \\
\hline & $\mathrm{T} / \mathrm{K} 298.15$ & 303.15 & 308.15 & $\begin{array}{l}313.15 \\
\text { (A) }\end{array}$ & 298.15 & 298.15 & 298.15 \\
\hline S1 & 0.08 & 0.11 & 0.13 & 0.17 & 60.6952 & 357.35 & 0.99 \\
\hline S2 & 0.36 & 0.53 & 0.68 & 0.81 & 24.9762 & 416.31 & 1.31 \\
\hline S3 & 0.56 & 0.79 & 1.13 & 1.33 & 14.0768 & 455.81 & 1.48 \\
\hline S4 & 0.75 & 1.03 & 1.40 & 1.79 & 6.8968 & 450.19 & 1.48 \\
\hline S5 & 0.08 & 0.13 & 0.20 & $\begin{array}{l}0.30 \\
\text { (B) }\end{array}$ & 61.3196 & 659.37 & 2.01 \\
\hline S1 & -0.82 & -0.81 & -0.81 & 0.43 & 20.48 & 13.36 & -0.11 \\
\hline S2 & 0.48 & 0.46 & 0.46 & 1.63 & -11.95 & 14.78 & -0.01 \\
\hline S3 & 1.45 & 1.47 & 1.51 & 4.64 & -36.05 & 44.03 & 0.26 \\
\hline S4 & 1.85 & 1.83 & 1.80 & 6.08 & -46.09 & 30.55 & 0.05 \\
\hline S5 & 1.40 & 1.43 & 1.45 & 4.15 & -34.75 & 37.39 & 0.24 \\
\hline
\end{tabular}

(A) Arginine only (B) Arginine + Gluten

Where $\mathrm{A}$ is the frequency factor, $\mathrm{R}$ is the gas constant and $\mathrm{Ea}$ is the Arrhenius activation energy of the transport process in different concentrations of arginine in absence and in presence of gluten. From the plot of $\log \Lambda_{0} v s .1 / \mathrm{T}$, the Es values have been computed from the slope (=-Ea/2.303R) and are recorded in Table 2. The free energy change, $\Delta G^{0}$ for the association process is calculated from.

$$
\Delta \mathrm{G}^{0}=-\mathrm{RT} \ln \mathrm{K}_{\mathrm{A}}
$$

The heat of association $\Delta \mathrm{H}^{0}$ is calculated from the slope of the plot of $\ln \mathrm{K}_{\mathrm{A}} v \mathrm{~s} .1 / \mathrm{T}$ and the entropy change, $\Delta S^{0}$ from Gibbs - Helmholtz equation,

$$
\Delta \mathrm{G}^{0}=\Delta \mathrm{H}^{0}-\mathrm{T} \Delta \mathrm{S}^{0}
$$

The values of $\Delta \mathrm{G}^{0}, \Delta \mathrm{H}^{0}$ and $\Delta \mathrm{S}^{0}$ at $298.15 \mathrm{~K}$ are given in Table 3. It can be seen from Table 2 that the values of Es in case of the individual systems (S1to S5) in presence and absence of gluten are positive, where as the arginine overall system showed a negative 
activation energy but in presence of gluten showed positive values. The positive $\Delta \mathrm{G}^{0}$ values for the systems of arginine without gluten indicate that the dissociation process predominates over the association where as in presence of gluten the $\Delta \mathrm{G}^{0}$ values are negative except that of the lowest concentration $(0.1 \mathrm{M})$ of arginine. This observation ascribed to the fact that, in presence of gluten, arginine undergoes preferential association. The positive $\Delta \mathrm{H}^{0}$ values for the systems containing arginine show that the association processes are energy consuming. In presence of gluten the values of $\Delta \mathrm{H}^{0}$ are found to be negative indicating the association process to be exothermic except that of the system containing the highest concentration $(0.5 \mathrm{M})$ of arginine. The $\Delta S^{0}$ was found to be positive in all arginine systems, whereas in presence of gluten, the value is negative at two lower concentrations but at higher concentrations the value is positive. The positive $\Delta S^{0}$ values indicate the ions are hydrated in these systems.

\section{Conclusion}

The solubility enhancement of gluten was examined in presence of arginine. It was observed that, arginine enhances the solubility of gluten by 15.71 folds as compared to that in water. The conductometric analysis of the systems was carried out at the temperature range between $298.15 \mathrm{~K}$ and $313.15 \mathrm{~K}$, to understand the solute solvent interaction and for the determination of the related thermodynamic parameters. The limiting molar conductivities of arginine in presence of gluten are higher as compared to that of arginine systems. This confirms the molecular association aided solubility enhancement of gluten.

\section{References}

1. Al-Maaieh A and Flanagan D R, J Pharm Sci., 2002, 91(4), 1000-1008.

2. Arakawa T, Bhat R and Timasheff S N, Biochemistry, 1982, 21(25), 6545-6552.

3. Arakawa T and Tsumoto K, Biochem Biophys Res Commun., 2003, 304(1), 148-152.

4. Arakawa T, Bhat R and Timasheff S N, Biochemistry, 1990, 29, 1914-1923.

5. $\quad$ Arakawa T, Kita Y and Koyama H, Int J Pharm., 2008, 355(1-2), 220-223.

6. Kita Y and Arakawa T, Lin T Y and Timasheff S N, Biochemistry, 1994, 33(50), 15178-15189.

7. $\quad$ Lin T Y and Timasheff S N, Protein Sci., 1996, 5(2), 372-381.

8. $\quad$ Timasheff S N, Arakawa T, J Crystal Growth., 1988, 90, 39-46.

9. $\quad$ Crowley P B and Golovin A, Proteins, 2005, 59(2), 231-239.

10. Woods A S, J Proteome Res., 2004, 3, 478-484.

11. Dash U N, Mohapatro J R and Lal B, J Mol Liq., 2006, 124, 13.

12. Solanki C S, Mishra P, Talari M K, Tripathy M K and Dash U N, E-J Chem., 2012, 9(1), 21-26.

13. Poochkian G D and Gradock J C, J Pharm Sci., 1974, 68, 728-732.

14. Gurney R W, Ionic processes in solutions, McGraw Hill, Newyork, 1953.

15. Shedlovsky T and Kay R L, J Phys Chem., 1956, 60, 151.

16. Fuoss R, J Phys Chem., 1975, 79, 525.

17. Fuoss R, J Phys Chem., 1978, 82, 2427.

18. Yan X, Wang X, Xing R and Wang J, J Chem Thermodynamics, 2009, 41(12), 1343-1349.

19. Singh R D, Rastogi P P and Gopal R, Can J Chem., 1968, 46, 3525.

20. Coetzee J F and Ritchi C D, Solute solvent interactions; Marcell Dekkar: Newyork and Basel, 1976. 